\title{
ASSESSING STUDENT EXPERIENCES: ASSIGNMENT DESIGN TO ENCOURAGE STUDENT REFLECTION AND FEEDBACK ON PROGRAM-LEVEL EFFECTIVENESS
}

\author{
Lydia Wilkinson and Alison McGuigan \\ University of Toronto \\ lydia.wilkinson@utoronto.ca
}

\begin{abstract}
Within our second year communication course in Chemical Engineering an assignment asks students to reflect upon their experience through the second year to identify courses and suggest course or program-level recommendations that deserve funding. Student presentations for this assignment provide a method of capturing student responses to their current curriculum and integrating their values and ideas into future planning.

These presentations propose a range of initiatives to improve the educational experience: cross-curricular integration, opportunities for professional development and exposure to industry, increased lab time, hands-on learning through practical projects, introduction or increased use of engineering software, improvements to facilities or equipment, increased teaching assistant support, and better use of instructional technology. The responses as a whole indicate that this activity helps students to better understand the interconnectedness of their curriculum, and the challenge of orchestrating program-level change.
\end{abstract}

Keywords: Program-level assessment, course review, student feedback, student engagement, assignment design

\section{INTRODUCTION}

While instructors benefit from regular feedback provided in course evaluations, and sometimes informally through mid-course reviews, opportunities to situate one's course at the program-level are less frequent and straightforward. Faculty-level committees and conversations with colleagues provide forums to share and refine program-level objectives, but these mechanisms do not necessarily capture and propagate student responses to their learning. Literature on program-level evaluation acknowledges the importance of engaging with students as primary stakeholders in program planning [2], but designing mechanisms that can accurately measure and share the full range of student experiences is challenging
[3]. Student focus groups, class representatives and town hall style meetings can provide a wealth of information, but these systems often elicit feedback from only a handful of engaged students. This current situation then, leaves instructors with only some insight into the student experience in their course within the larger curriculum, and misses an opportunity to encourage students to reflect upon and participate in curriculum planning at the program-level.

Within our second year communication course for Chemical Engineers at University of Toronto we have developed an assignment that responds to this gap by asking our students to analyze the existing curriculum and recommend and provide a rationale for changes. The project asks students to imagine that they represent the Department of Chemical Engineering on a pitch to a group of interested donors. They must present a plan that earmarks the donor funds for a particular course-based or program-level improvement. Students are provided with the following instructions: "Your presentation should first review the key learning outcomes of the $2^{\text {nd }}$ year curriculum to consider how your courses work together to develop your skills and knowledge, and to identify gaps or areas for improvement in this curriculum. You should consider the type of evidence that will best support your argument for spending the donor's money. You could draw on outside sources (research papers or current event articles) in support of your course, as well as drawing on your own experience as a student in this course. As a representative of the University of Toronto, you are expected to present professionally. As an expert on your subject you should be prepared to explain technical information clearly to a nontechnical audience."

This activity provides us with a clearer understanding of student perceptions of the second year curriculum and our course within it. Through this information we gain insight into how our course, which incorporates core course assignments from across the curriculum, is effectively supporting or disrupting these other class experiences. It also encourages students to actively engage with programlevel objectives and their classroom experience, to consider why they are learning what they are learning and how this aligns with their expectations and needs. This paper will 
review student responses to this assignment over the last two years to examine the use of this tool as a means of eliciting student input into their education at the programlevel.

\subsection{Background and Motivation}

Our second year communication course was developed in response to a call for more integrated communication instruction from both students and faculty. As instructors we were aware of the benefits of this integration: when our students practice skills using core assignments in our classroom they more immediately see the relevance of the strategies that we teach. While planning the course we worked to identify activities and assignments across the curriculum that could work as a vehicle for communication instruction and development, and these points of intersection now provide the material for many of our activities. For example, when learning how to use a mindmap for idea generation and planning we ask students to use a recently assigned project from their Fluid Mechanics course. When guiding our students through research and search strategies we generate keywords for an Economics project that they have just begun. This approach has helped us to increase the relevance of our instruction, but it's success is dependent upon our ability to identify and leverage opportunities and deficits within the current curriculum. Our students can often provide the greatest insights into this curriculum.

We introduced this assignment then as an opportunity to gather data on course content areas from across second year, while also encouraging our students to more actively reflect on and engage with curriculum at the program-level. This type of reflection can help students to identify connections between different courses and skills that can be transferred between different subject areas [1]: a central skill for the success of communication training in our course.

Results from these student presentations provide useful information about the ways that our students are responding, engaging with and valuing courses within our institution and department. Their insights however can also be applied to other contexts; within their discussion of specific courses students shared their responses to and preference for particular pedagogical approaches and instructional/learning styles, and their ideas about not only what is delivered but how it is delivered are equally valuable to other institutions.

\subsection{Methodology}

Presentation slides were reviewed from all six tutorial sections for the 2014/2015 and 2015/2016 academic years, totaling 69 groups (33 for year one and 36 for year two). The content of these slides was coded by course or program-level recommendation, and categorized according to the nature of the proposed intervention: cross-curricular integration, opportunities for professional development and exposure to industry, increased lab time, hands-on learning through practical projects, introduction or increased use of engineering software, improvements to facilities or equipment, increased teaching assistant support, and better use of instructional technology.

\subsubsection{Intervention Categories}

Cross-curricular integration: This category includes recommendations for activities and projects that tie courses together, as well as initiatives that integrate concepts and applications between courses, such as the addition of Applied Chemistry labs that reinforce content from Environmental Engineering.

PD/Industry exposure: This category includes recommendations for industry interaction, such as site visits to plants and guest speakers or industry experts in various courses. It also includes initiatives designed to develop students' professional identities, like resume and cover letter instruction and job search support. Some recommendations move beyond industry jobs to propose activities designed to expose students to possible future research fields.

Lab time: This category includes requests for increased lab hours in Applied Chemistry and the addition of a lab component in other lecture-based courses.

Practical projects: This category includes recommendations for practical projects including assignments with physical design elements, field experience-for example onsite sampling in environmental chemistry - and simulations.

Engineering software: This category includes recommendations for purchase of and instruction in simulation software for process engineering, like Aspen HYSYS and COCO. It also includes more class time and training for existing technologies like MATLAB and VBA.

Improvements to facilities: This category includes recommendations for new types of equipment and replacement of old or damaged equipment; typically, these improvements are recommended for the Applied Chemistry lab course.

TA support: This category includes requests for increased TA hours, often to facilitate additional lab modules in some courses. It also covers suggestions for improved TA training.

Instructional technology: This category includes recommendations for implementing new technologies to improve program and course organization, such as timetabling software to share deliverables between courses, and centrally maintained databases on particular topics. It also includes improved use of existing course management software via instructor training, and development of online content and instruction. 


\section{RESULTS}

\subsection{Course Recommendations}

The following table provides a breakdown of courses selected for financial support. While the majority of groups centered their discussion around improvements to one particular course, eleven presentations proposed program-level initiatives that would be implemented across multiple courses, or solutions focusing on administrative changes such as increased support for or training of faculty; these approaches are broken down under program-level initiatives.

Table 1: Recommendations.

\begin{tabular}{|l|l|l|}
\hline \multicolumn{1}{|c|}{ Course Focus } & \multicolumn{2}{c|}{$\begin{array}{c}\text { Number of } \\
\text { Responses }\end{array}$} \\
\hline & $\mathbf{2 0 1 4 / 1 5}$ & $\mathbf{2 0 1 5} / \mathbf{1 6}$ \\
\hline Applied Chemistry Lab & 12 & 9 \\
\hline Process Engineering & 4 & 7 \\
\hline Communication & 3 & 3 \\
\hline Fluid Mechanics and & 3 & 3 \\
\hline $\begin{array}{l}\text { Engineering strategies } \\
\text { practice }\end{array}$ & 3 & 2 \\
\hline $\begin{array}{l}\text { Concepts in Chemical } \\
\text { Engineering }\end{array}$ & 2 & 2 \\
\hline Organic Chemistry & 1 & 1 \\
\hline Statistics & 1 & 1 \\
\hline Program-level initiatives & 2 & 4 \\
\hline Hands-on projects & 1 & 2 \\
\hline Instruction in programming & 1 & 1 \\
\hline Faculty training & \multicolumn{2}{|l}{} \\
\hline
\end{tabular}

\subsection{Proposed Approach}

The list of proposed courses captures the subject areas that students find most central to their education in the second year. Their suggested strategy for spending and improvement provides further insight into the types of educational interventions that can most improve their experience. The table below lists the frequency of responses in each of the eight categories of intervention. Many groups proposed multiple types of improvement for a single course, which accounts for the larger response size than number of participant groups.

Table 2: Frequency of intervention type.

\begin{tabular}{|l|l|l|}
\hline \multicolumn{1}{|c|}{ Intervention type } & \multicolumn{2}{c|}{$\begin{array}{c}\text { Number of } \\
\text { responses }\end{array}$} \\
\hline & $\mathbf{2 0 1 4 / 1 5}$ & $\mathbf{2 0 1 5 / 1 6}$ \\
\hline TA support & 19 & 13 \\
\hline PD/Industry exposure & 13 & 17 \\
\hline Improvements to facilities & 12 & 7 \\
\hline Lab time & 9 & 10 \\
\hline
\end{tabular}

\begin{tabular}{|l|l|l|}
\hline Practical projects & 7 & 5 \\
\hline Instructional technology & 7 & 5 \\
\hline Cross-curricular integration & 7 & 2 \\
\hline Engineering software & 6 & 13 \\
\hline
\end{tabular}

\section{DISCUSSION}

Student responses to this assignment provide insight into the perceived importance of particular courses as well as pedagogical approaches. Some of the most prominent trends, discussed below, speak to the value of assignments like this one in encouraging students to consider how their learning functions beyond individual courses as a complete educational experience.

\subsection{Value of Hands-on Learning}

A desire for more practical experience is evident in both the most popular course for investment, Applied Chemistry, and many intervention strategies. This interest in applied learning is not surprising given the nature of our field: our students after all are completing a degree in applied science. The number and variety of opportunities that groups identified however, reveal the value of expanding hands-on instructional approaches beyond the courses that typically focus on application (i.e. lab courses). Groups suggested that practical projects could be incorporated into Process Engineering, Fluid Mechanics and Environmental Engineering, with the integration of process simulation software in the former and field experience in the latter. The importance placed on practical application is also evident in the TA category, where smaller TA to student ratios were seen as supporting success in the lab environment.

Students were required in this assignment to integrate evidence from multiple sources to support their claims, and arguments for the value of this type of instruction frequently utilized literature from engineering education on the importance of applied learning to increase retention. Students also argued about their own engagement in practical subjects and compared their success in Applied Chemistry to their success in largely theoretical courses, to argue that their performance was supported through the understanding made possible by applied learning. While there are many many factors that may explain differences in grade averages between courses, students' discussion of this success again spoke to their engagement with applied material over lecture equivalent in other courses. Finding opportunities for practical applications in more courses and via course partnerships could help to encourage immediate understanding of the importance of key concepts and techniques beyond the classroom environment. 


\subsection{Increased Understanding of Institutional Systems}

While students used the presentation to articulate their educational and instructional values, the process of researching and reflecting upon the project also helped to increase understanding of the interconnectedness of various systems within the university, faculty and department. This shift in understanding is most evident in year one, when 19 of the 36 groups suggested a need for increased TA support. These responses were likely effected by the institutional climate at that time: this project was completed during a university wide TA strike, and three of the six tutorial sections for the course were missing instructors through this period. While the particular context likely made students hyperaware of the importance of TAs in our institution's instructional model, media coverage of union negotiations also publicized TA wages and workload norms, and provided our students with up-to-date information to use when calculating costs for implementation.

Some groups also developed an understanding of the importance of administrative staff and faculty in monitoring timetabling and overseeing course due dates and scheduling of midterms and final exams. Their research into these issues led to suggestions around technical solutions such as project management and scheduling software, but also more human-centered approaches, such as consistent communication between faculty and administrative staff, to ensure that student workloads remain reasonable.

The level of institutional analysis precipitated by this assignment seems in the short term to have made these two years more aware of the complexity and interrelatedness of the systems that support their education. Groups were forced to move beyond simple recommendations to consider the amount of time and in turn money necessary for each solution, as well as the groups and individuals involved. Whether our students retain this understanding beyond our course is something that can best be measured in the coming years, but even in the short-term, this type of knowledge may help students to better navigate their institutional environment.

\subsection{Interest in Professionalization}

A significant number of groups across both years made recommendations for increased industry exposure through site visits, guest speakers and opportunities to work with 'real-world' clients. Surprisingly, many of the arguments for this increased interaction rested on the belief that industry experts had particular expertise that instructors lacked, even within courses where this type of industry partnership is non-traditional. Often students suggested that experts were more persuasive proponents of the value of particular subjects, especially in a course like communication, where students are often initially resistant. This type of persuasion may be relatively easy to incorporate via industry testimonials and even limited involvement in core subjects.

Groups also expressed a desire for more job-search related activities, such as resume clinics, cover letter writing instruction and mock-interviews. Within our institution these responsibilities are typically provided by the Engineering Career Centre, and these recommendations may point to changes that could be made within that unit; but they also may indicate a need to educate our students about these available resources and encourage them to make use of support mechanisms outside of the classroom environment. This gap is one that we are currently countering in our own planning for the communication course next year.

\section{SUCCESS AS A PROGRAM OR COURSE ASSESSMENT MEASURE}

As is evident from the discussion above, this exercise exposed students to the faculty and department's ecosystem. On the one hand, this made it possible for groups to generate ideas that could be applied to streamline course loads and expectations as well as to improve methods of instruction through central training and staffing. On the other hand, it made students more aware of the challenges of making decisions and exacting change within a complex system; this knowledge may foster greater understanding and collaboration between faculty, staff and students, but may also result in more cynicism or dissatisfaction with institutional bureaucracy. Regardless of these long-term outcomes, the exercise encouraged students to consider the curriculum as a whole, and also provided insight into their understanding of this whole.

These presentations also provided other types of feedback that would be difficult to capture through traditional course measures. This project (in both years) was scaffolded by a mind-mapping exercise in which students sketched out the overall curriculum to isolate connections and overlap between courses as well as areas for improvement. Their mind-map provided a visual model of the interrelatedness of courses, and made clear to students the overlap of concepts and skills across these courses. In turn, within the presentations, students shared these connections and proposed ideas to take them further, by devising cross-curricular initiatives, such as interconnected labs, and cross-course projects to build cohesion and reinforce knowledge. This area of need is also difficult to capture through traditional course-based assessment tools. While many educators will acknowledge the value of enforcing ideas and approaches between courses, our students are also aware of its importance. 
Finally, this project provides particular insights that underlie the value placed on certain courses and activities. Our students can speak to the importance of applied learning within the context of a particular course, but have few mechanisms to call more generally for a shift in focus from the theoretical to the applied. This assignment gave them an outlet to look closely at their education, its outcomes as articulated in the curriculum, and their own perceived success in meeting these outcomes under the current pedagogical approach. Through their presentations they could share their ideas with faculty who are interested in engaging with them in a discussion about the future direction of engineering education broadly and their educational experience specifically.

\section{CONCLUSION AND FUTURE DIRECTIONS}

This assignment provides our students with an important vehicle to understand and reflect upon their experience at the course and program-level; at the same time, it provides us with a unique method to gather information about how best to engage our students and support their success. We will continue to use this assignment as an informal tool for gathering student responses to our program and their ideas around effective pedagogy. Their insights will continue to inform the way that we deliver content and will be shared with our colleagues. A follow-up study with our first and second cohorts in their fourth years will measure the impact of this exercise in increasing program-level awareness in the long-term.

\section{References}

[1] Bary R, Rees M, "Is (self-directed) learning the key skill for tomorrow's engineers?" European Journal of Engineering Education, vol. 31, no. 1, March 2006, pp. 73-81.

[2] Ives C, McAlpine L, Gandell T, "A systematic approach to evaluating teaching and learning initiatives in post-secondary education," The Canadian Journal of Higher Education, vol. 39, no. 2, 2009, pp. 45-76.

[3] Joint Committee on Standards for Educational Evaluation, The Program Evaluation Standards: How to Assess Evaluations of Educational Programs, Thousand Oaks, CA: Sage Publications, 1994. 